\title{
QUALIDADE DO CAFÉ CONILON SUBMETIDO À SECAGEM EM TERREIRO HÍBRIDO E DE CONCRETO
}

\author{
Conilon coffee quality submitted to drying in hybrid terrace and concrete yard
}

\author{
Osvaldo Resende ${ }^{1}$, Paulo Cesar Afonso Júnior ${ }^{2}$, Paulo César Corrêa ${ }^{3}$, Valdiney Cambuy Siqueira ${ }^{4}$
}

\begin{abstract}
RESUMO
Avaliar a qualidade do café conilon (Coffea Canephora Pierre) depois da secagem em terreiro híbrido e de concreto, processado por via seca para as condições climáticas do Estado de Rondônia, foi o principal objetivo deste trabalho. O café foi colhido, manualmente, pelo sistema de derriça no pano, com teor de água de aproximadamente $50 \%$ (b.u.), separado por diferença de massa específica em três grupos: cerejas, boia e café mistura. Posteriormente, cada um dos grupos foi dividido em dois lotes e submetidos à secagem em terreiro híbrido e terreiro de concreto. A análise sensorial foi realizada pela degustação por especialista e a qualidade química do produto foi avaliada por meio das análises da acidez titulável, sólidos solúveis totais e condutividade elétrica. Conclui-se que o tempo necessário para que os cafés boia, mistura e cereja atingissem o teor de água de 9,5 0,5 (\%b.u.) foi de 168 horas no terreiro de concreto e no terreiro híbrido foi de 48,54 e 60 horas, respectivamente. O café submetido à secagem em terreiro de concreto obteve melhor qualidade em comparação ao café secado em terreiro híbrido, decorrente da taxa de remoção de água mais lenta, em média 3,1 vezes menor que no terreiro híbrido, e em função das condições climáticas favoráveis à secagem em terreiro de concreto.
\end{abstract}

Termos para indexação: Pós-colheita, redução do teor de água.

\begin{abstract}
The main objective of this work was to analyze the conilon (Coffea Canephora Pierre) coffee berry quality after drying in hybrid terrace and concrete yard processed by dry and drying under the climatic conditions of the state of Rondônia. The coffee berries were manually harvested on the cloth, at moisture content of approximately $50 \%$ (w.b.), separated by differences of bulk density in three types: cherries, float and coffee mixture. Thereafter, each group was divided into two lots and subjected to drying in hybrid terrace and concrete yard. The sensory analysis was carried out by specialist tasting and the chemical quality was assessed by analysis of acidity, soluble solids and electrical conductivity. The results showed that the drying time needed for all the types to reach the moisture content of $9.5 \pm 0.5$ (\% w.b.) was 168 hours in the concrete yard, and for hybrid terrace was 48,54 e 60 hours respectively. The coffee berry drying in concrete yard obtained better quality compared to the hybrid terrace, mainly due to smaller rate of removal of water in drying system, on average three times lower than in the concrete yard and according to the fortunate climatic conditions in the drying concrete yard.
\end{abstract}

Index terms: Post harvest, moisture content reduction.

(Recebido em 29 de outubro de 2009 e aprovado em 7 de maio de 2010)

\section{INTRODUÇÃo}

O café é a cultura perene mais difundida no Estado de Rondônia, que é o quinto maior produtor de café do país, apresentando na safra de 2008/2009, a produção de 1.547 .000 sacas, que representa $3,91 \%$ da produção nacional, com produtividade média de 10,02 sacas por hectare. Considerando apenas a espécie de café cultivada em Rondônia (Coffea Canephora Pierre), o estado é o segundo maior produtor sendo responsável por $14,58 \%$ da produção brasileira, superado apenas pelo Espírito Santo com 71,68\% (CONAB, 2010).

A secagem em terreiros, com ar natural, é possível em ambientes com baixa umidade relativa do ar e pouca nebulosidade. A principal vantagem desse método é a economia de energia, porém apresenta o inconveniente de exigir extensas áreas e depender dos fatores climáticos, que, sendo desfavoráveis, retardam o processo, comprometendo a qualidade do produto (CAMPOS et al., 1999; SILVA \& BERBERT, 1999).

Recentemente têm sido realizados inúmeros trabalhos com o objetivo de estudar a secagem do café em diversas condições. No entanto, a maioria destas investigações foram realizadas para descrever a secagem do café da espécie Coffea arábica (ANDRADE et al., 2003; REINATO et al., 2003a; REINATO et al. 2003b; RIBEIRO et al., 2003; SILVA et al., 2003; AFONSO JÚNIOR et al., 2004; CORRÊA et al., 2006;

\footnotetext{
1'Instituto Federal de Educação, Ciência e Tecnologia Goiano/IFGoiano - Campus Rio Verde - Rodovia Sul Goiana - Km 01 - 75901 -970 - Rio Verde, GO osvresende@yahoo.com.br

²Empresa Brasileira de Pesquisa Agropecuária/EMBRAPA/CAFÉ - Brasília, DF

3Universidade Federal de Viçosa/UFV - Departamento de Engenharia Agrícola - Viçosa, MG

${ }^{4}$ Instituto Federal de Educação, Ciência e Tecnologia Goiano/IFGoiano - Rio Verde, GO
} 
AFONSO JÚNIOR et al., 2006; BORÉM et al., 2008a; BORÉM et al., 2008b; LACERDA FILHO et al., 2006; SANTOS et al., 2009), sendo restritos os trabalhos para descrever a secagem do café da espécie Coffea Canephora (RESENDE et al., 2007; RESENDE et al., 2009a; RESENDE et al., 2009b).

Uma alternativa para a secagem do café em regiões que apresentam elevada umidade relativa do ar durante o período de colheita é a utilização do terreiro híbrido (SILVA et al., 2000), que representa a possibilidade de combinação da condução do processo de secagem com ar natural e aquecido. Para as condições climáticas do estado de Rondônia, caracterizado pelo clima tropical quente e úmido, o terreiro híbrido apresenta acentuado potencial de utilização pelos produtores, em razão, essencialmente, ao seu baixo custo de instalação, facilidade de manuseio do produto e pela rapidez na secagem.

Donzeles et al. (2007a) constataram que, para as condições climáticas da região da Zona da Mata de Minas Gerais, o terreiro híbrido secou em média quatro vezes mais rápido o café cereja descascado (Coffea arabica L.) comparativamente ao terreiro de concreto.

Segundo Palacin et al. (2009),De acordo com Abrahão et al. (2010), para atender as exigências do mercado consumidor os cafeicultores necessitam, cada vez mais, dedicar grande atenção às diversas etapas da produção como condução da lavoura, colheita e pós-colheita, já que os atributos físicos e sensoriais de sabor e aroma, influenciados por estes processos, são decisivos para a classificação dos cafés. Algumas operações de pré-processamento podem influenciar na qualidade do café. E, de acordo com estes pesquisadores, a secagem é a operação considerada crítica por propiciar estresses térmicos, desenvolvimento de fungos indesejáveis, adição de odores de fumos e, ou de outros contaminantes nos frutos ou nos grãos, dependendo da técnica empregada na operação.

Assim, avaliar a qualidade do café conilon (Coffea Canephora Pierre) depois da secagem em terreiro híbrido e de concreto, processado por via seca e para as condições climáticas do Estado de Rondônia, foi o principal objetivo neste trabalho.

\section{MATERIAL E MÉTODOS}

O trabalho foi desenvolvido na Unidade Experimental da Embrapa e no Departamento de Agronomia do campus da Universidade Federal de Rondônia - UNIR, situados nos municípios de Ouro Preto do Oeste e Rolim de Moura - RO, respectivamente.

Foram utilizados frutos de café (Coffea Canephora Pierre), variedade conilon, procedentes do município de Ouro Preto do Oeste, RO. O café foi colhido, manualmente, pelo sistema de derriça no pano, com teor de água de aproximadamente $50 \%$ (b.u.). Depois da colheita, o produto foi separado por diferença de massa específica em três grupos: cerejas, boia e café da roça ou mistura, que representa a forma como o produto vem da lavoura sem passar pelo lavador. Posteriormente, cada um dos grupos foi dividido em dois lotes e submetidos à secagem em terreiro híbrido e terreiro de concreto.

Para a secagem do produto no terreiro de concreto, os lotes de café foram individualizados em células de $4 \mathrm{~m}^{2}$, espalhados em camadas de $5 \mathrm{~cm}$ de espessura e revolvidos periodicamente ao longo do dia a cada intervalo de uma hora.

A secagem do café no terreiro híbrido foi realizada em um aparato experimental com área de $67,5 \mathrm{~m}^{2}$, contendo três células de 22,5 $\mathrm{m}^{2}$ cada uma, conforme ilustrado na Figura 1.

Utilizou-se como combustível para aquecimento do ar no terreiro híbrido o carvão vegetal, apresentando o teor de água de 2,13 (\%b.u.). A vazão de ar do ventilador foi calculada com o auxílio de um anemômetro digital de pás rotativas apresentando um valor médio de $64,98 \mathrm{~m}^{3} \mathrm{~min}^{-1}$. A vazão específica do ar foi $8,66 \mathrm{~m}^{3} \mathrm{~min}^{-1} \mathrm{~m}^{-2}$, determinada pela divisão da vazão do ar do ventilador pela área total da calha perfurada.

Durante o processo de secagem, em cada célula do terreiro híbrido a temperatura da massa de café foi monitorada em intervalos de três horas, com o auxílio de um termômetro digital, instalado em três pontos situados a $0,10 \mathrm{~m}$ de profundidade e distribuídos ao longo da leira formada pelo produto. Esta altura de coleta foi estabelecida para que se verificasse a temperatura em uma posição mediana da camada de grãos, e o monitoramento foi realizado a cada 1,5 horas depois do revolvimento dos grãos.

Os três lotes de café (cereja, boia e mistura) foram amontoados, separadamente em cada célula do terreiro híbrido, sobre a superfície do duto de ventilação (chapa perfurada) responsável pela distribuição do ar forçado e aquecido pela da massa de café, permitindo um processo contínuo de secagem do produto. Cada lote foi revolvido periodicamente a cada três horas e a camada de grãos formou um cone de $0,45 \mathrm{~m}$ de altura, sendo $0,25 \mathrm{~m}$ acima da chapa perfurada.

Os teores de água do café ao longo da secagem foram acompanhados a cada 3 horas no terreiro híbrido e diariamente no terreiro de concreto, sendo determinados pelo método da estufa, $105 \pm 1^{\circ} \mathrm{C}$, em três repetições homogeneizadas de $30 \mathrm{~g}$ até massa constante (BRASIL, 1992). A secagem foi interrompida quando os lotes de café atingiram o teor de água de 9,5 $\pm 0,5$ (\%b.u.). A temperatura e a umidade relativa do ar ambiente foram monitoradas por meio de psicrômetros. 
Depois da secagem o café foi beneficiado e encaminhado para a realização das análises. A determinação da composição química depois do beneficiamento foi avaliada por meio das análises da acidez total titulável, sólidos solúveis totais e condutividade elétrica.

A acidez total titulável foi obtida por titulação com $\mathrm{NaOH}$ 0,1 N (AOAC, 1990) e os sólidos solúveis totais foram obtidos de acordo com a técnica descrita na AOAC (1990).

O teste de condutividade elétrica foi realizado utilizando-se a "condutividade de massa" de acordo com Vieira (1994). Foram contadas e pesadas quatro subamostras de 50 grãos, de cada tratamento. As amostras foram colocadas em copos de plástico com $75 \mathrm{~mL}$ de água deionizada e mantidas em uma câmara com temperatura controlada a $25^{\circ} \mathrm{C}$, durante 24 horas. Depois desse período, foi efetuada a leitura da condutividade elétrica da solução de embebição por meio de condutivímetro. Os resultados foram expressos em $\mathrm{mS} \mathrm{cm} \mathrm{cm}^{-1} \mathrm{~g}^{-1}$ de amostra.

A análise sensorial do café conilon foi realizada pela degustação por especialista da área, estabelecendo notas entre 0 e 100, e descrevendo as características marcantes do sabor em cada amostra, utilizando-se o protocolo de análise sensorial da Coffee Quality Institute
(2009), elaborado de acordo com a metodologia proposta por Lingle (1986) para avaliação de cafés especiais.

$\mathrm{O}$ experimento foi montado segundo o esquema fatorial 3 x 2 (3 formas de preparo do café e 2 tipos de terreiro) em delineamento inteiramente casualizado, com três repetições. Os dados foram analisados por meio de análise de variância e as médias comparadas pelo teste de Tukey, adotando-se o nível de $5 \%$ de probabilidade.

\section{RESULTADOS E DISCUSSÃO}

Durante a realização dos testes de secagem, as condições ambientes se mostraram favoráveis a secagem em terreiros, apresentando valores médios de $23,4^{\circ} \mathrm{C}$ e $63,4 \%$ para a temperatura e umidade relativa, respectivamente. Já, a temperatura média do ar de secagem no secador híbrido foi de $58,6 \pm 4^{\circ} \mathrm{C}$ e a umidade relativa média apresentou valor de $8,4 \pm 3 \%$.

Na Figura 2, estão apresentados os valores da temperatura da massa de café medida ao longo do período de secagem no secador híbrido. Verifica-se que a temperatura média da massa do produto, monitorada a $0,10 \mathrm{~m}$ de profundidade, apresentou aquecimento ao longo da secagem para os cafés cereja, mistura e boia, chegando ao final da secagem com valores próximos à temperatura

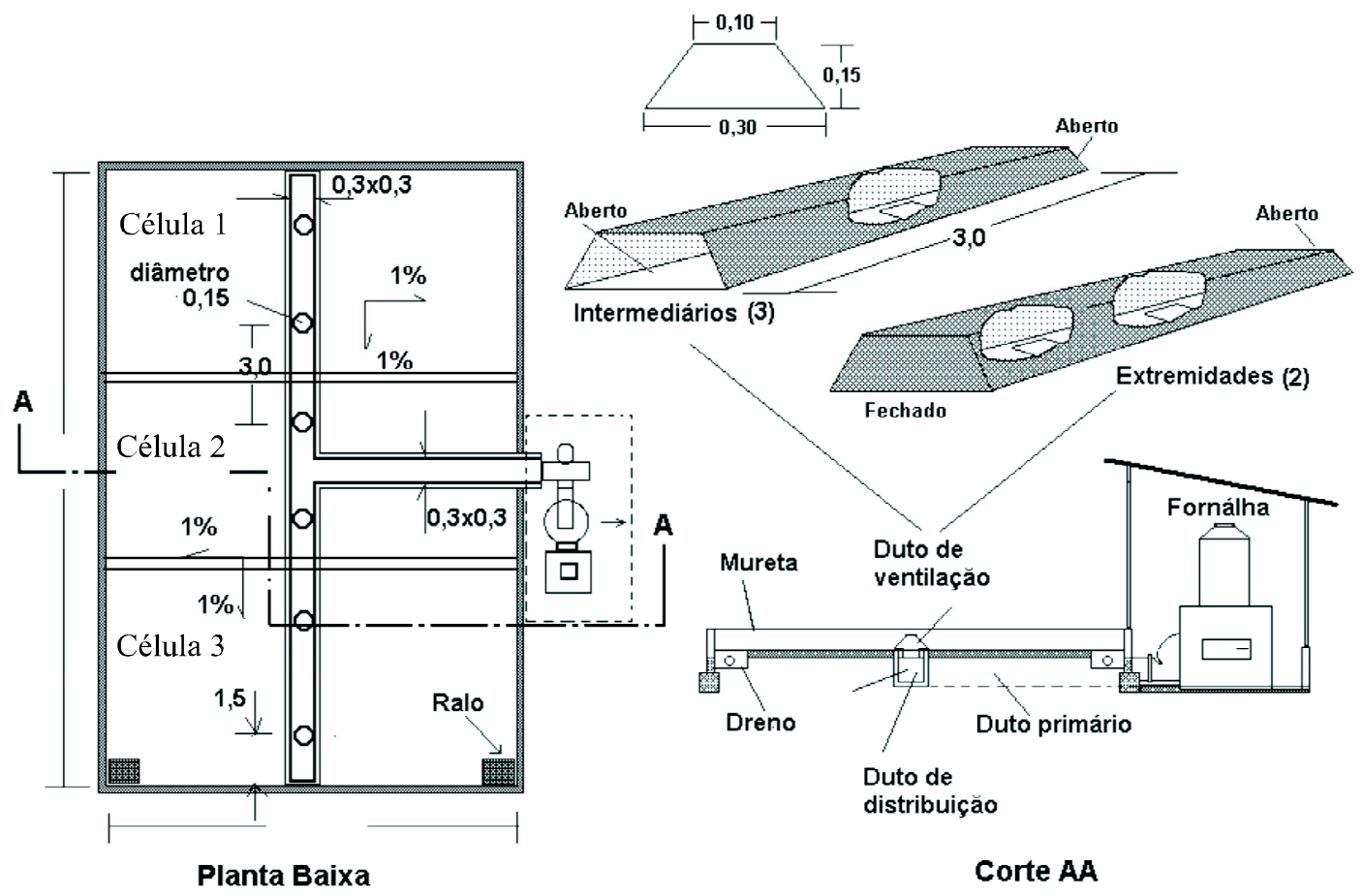

Figura 1 - Detalhes construtivos da unidade experimental do terreiro híbrido indicando as três células utilizadas. Adaptado de Silva et al. (2000). 
do ar de secagem. Nota-se que a temperatura da massa de café foi elevada e superior a $45^{\circ} \mathrm{C}$, recomendada como limite para obtenção de cafés com qualidade (REINATO et al., 2003b).

Na Figura 3, estão apresentados os valores médios do teor de água do café conilon durante a secagem em terreiro de concreto e em terreiro híbrido. Verifica-se que durante a secagem no terreiro de concreto o tempo necessário para que os lotes de café cereja, mistura e boia atingissem o teor de água, respectivamente, de 9,98; 8,98 e 9,37 (\%b.u.) foi de 168 horas.

$\mathrm{Na}$ secagem conduzida no terreiro híbrido (Figura 3B), os lotes de café necessitaram de tempos distintos para o final do processo, sendo de 48; 54 e 60 horas de secagem, respectivamente, para os cafés boia, mistura e cereja. Dessa forma, observa-se que o terreiro híbrido promoveu a secagem dos cafés boia, mistura e cereja em 120; 114 e 108 horas, respectivamente, antes que o terreiro de concreto, demonstrando a sua maior eficiência na secagem do produto, assim como executando a secagem, em média, 3,1 vezes mais rápido que no terreiro de concreto.

Resultados semelhantes foram observados por Donzeles et al. (2007a), que verificaram a velocidade de secagem no terreiro híbrido, quatro vezes maior que no terreiro de concreto para o café cereja descascado (Coffea arabica L.), e ainda por Donzeles et al. (2008), que analisando a secagem direta em leira do café cereja natural, em terreiro híbrido, e trabalhando com a temperatura do ar de secagem de $54,1 \pm 3,9^{\circ} \mathrm{C}$ observaram que para reduzir o teor de água do produto de 56,1 (\%b.u.) para 12,3 (\%b.u.) foram necessárias 54 horas de secagem; e que, para as condições climáticas da região da Zona da Mata de Minas
Gerais, o tempo de secagem do produto foi 6,7 vezes menor comparativamente ao terreiro de concreto.

Nas Tabelas 1 e 2, são apresentados os resultados das análises químicas realizadas no café conilon submetido à secagem em terreiro de concreto e em terreiro híbrido. Para as variáveis analisadas (acidez total titulável, sólidos solúveis totais e condutividade elétrica), não foram identificadas diferenças significativas na interação entre os terreiros e os lotes de café.

Nota-se, na Tabela 1, que o café secado no terreiro híbrido obteve os maiores valores de acidez total titulável em relação ao produto que teve a secagem em terreiro de concreto. Resultados semelhantes foram observados por Borém et al. (2008a), onde o aumento da acidez titulável total pode ter ocorrido, principalmente, por causa das concentrações de ácidos provenientes das degradações provocadas pela temperatura de secagem. E como a temperatura média do ar de secagem neste trabalho foi de $58,6 \pm 4^{\circ} \mathrm{C}$ promoveu efeito similar, fato comprovado na Tabela 2, uma vez que os grãos submetidos à secagem no terreiro híbrido apresentaram maior condutividade elétrica e, possivelmente, maior degradação das membranas. Leite et al. (1996) afirmam que os frutos imaturos apresentam menores teores de acidez que os frutos boia e café mistura, entretanto para o presente trabalho não foram verificadas diferenças nos valores de acidez total titulável para os frutos cereja, mistura e boia.

Ainda na Tabela 1, percebe-se que a secagem dos frutos no terreiro de concreto promoveu nos grãos a obtenção de maiores valores dos sólidos solúveis comparativamente ao café secado no terreiro híbrido. Os

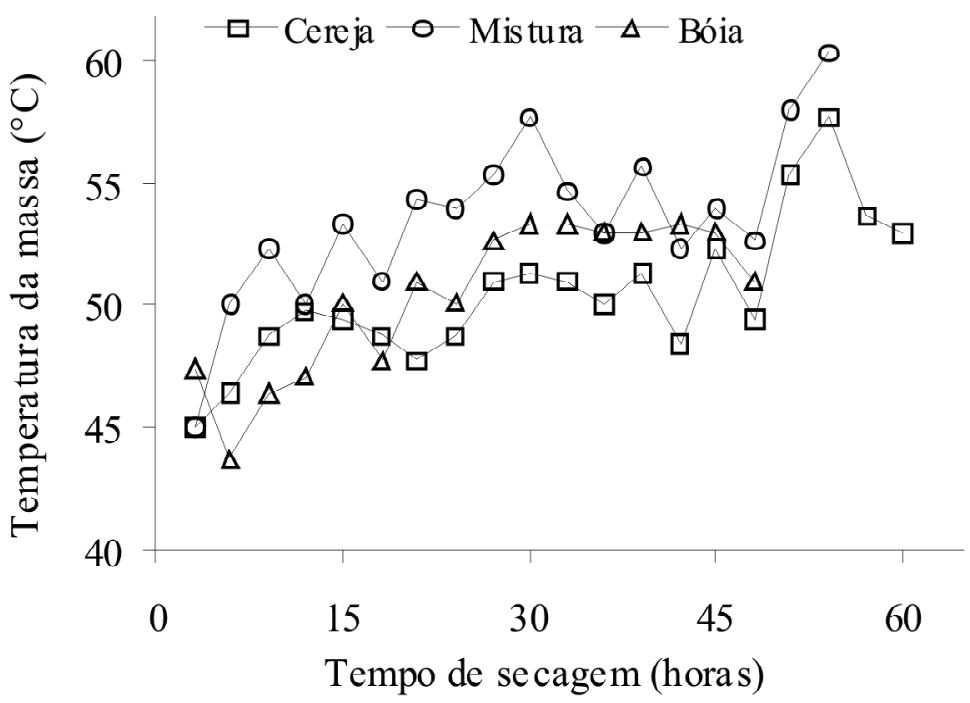

Figura 2 - Temperatura da massa dos cafés cereja, mistura e boia durante a secagem em terreiro híbrido. 
açúcares também estão relacionados com a qualidade da bebida, as quantidades dependem principalmente da espécie e local de cultivo do cafeeiro, além do estádio de maturação dos frutos (CAMPA et al., 2004). Essa característica é de fundamental importância para a produção do café da espécie Coffea canephora, em virtude, principalmente, da sua intensa utilização para a indústria de café solúvel ou mesmo para a formação de "Blends" com o café arábica. No entanto, operações de pós-colheita podem ocasionar variações nos teores de açúcares (LOPEZ et al., 2000). Resultados similares foram obtidos por Borém et al. (2008a), onde o aumento da temperatura de secagem influenciou nos menores valores de açúcares redutores dos grãos de café despolpados e naturais.

$\mathrm{Na}$ Tabela 2, verifica-se que a condutividade elétrica foi significativamente maior para os frutos submetidos à
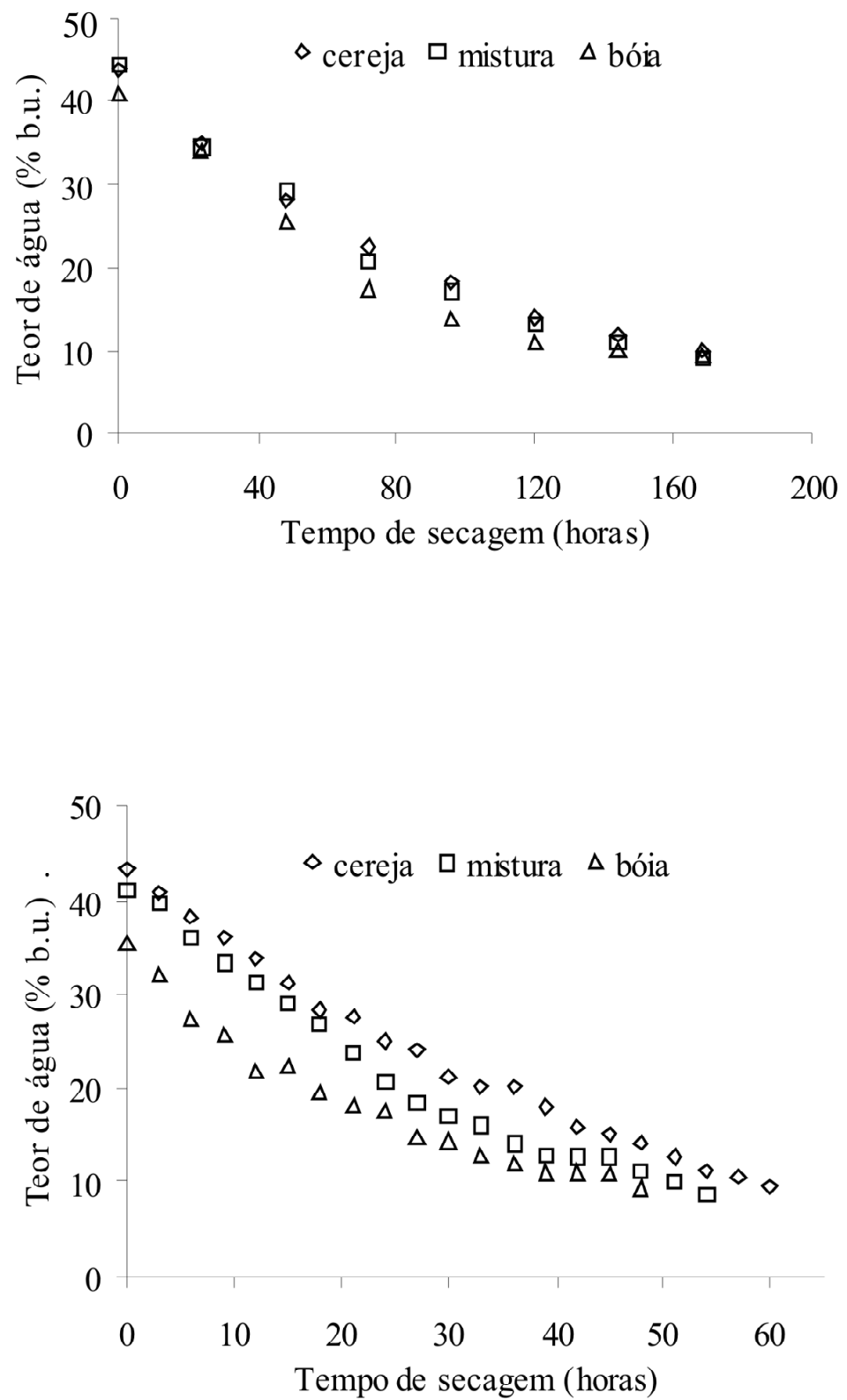

Figura 3 - Teores de água (\%b.u.) do café conilon cereja, boia e mistura ao longo do tempo de secagem (horas) em terreiro de concreto (A) e híbrido (B). 
secagem no terreiro híbrido comparativamente ao terreiro de concreto, indicando uma maior degradação das membranas celulares do produto, em razão da maior taxa de remoção de água neste sistema de secagem, em média 3,1 vezes mais rápido que no terreiro de concreto. Em relação aos tipos de café, observa-se que a condutividade elétrica foi diferenciada apresentando valores de 109,77; 101,09 e $98,11 \mathrm{mS} \mathrm{cm}^{-1} \mathrm{~g}^{-1}$ para os cafés cereja, boia e mistura, respectivamente. Seria esperado que o café cereja apresentasse menores valores de condutividade elétrica, pois o café mistura apresenta ainda certa percentagem de grãos verdes que não possuem sua estrutura celular completamente desenvolvida, e o café boia por já ter passado do ponto de colheita ideal apresenta um potencial maior de injúrias. No entanto, para a secagem do café conilon nos terreiros híbrido e de concreto, esse fato não foi verificado, possivelmente as elevadas taxas de secagem promovidas no terreiro híbrido influenciaram excessivamente a danificação mecânica no café cereja que permaneceu mais tempo em contato com as condições de temperatura e umidade relativa do ar de secagem (60 horas). Segundo Borém et al. (2008b), a secagem do café cereja descascado com ar aquecido a $60^{\circ} \mathrm{C}$, ocasionou a união e a ruptura das vesículas e das membranas, causando obstrução dos espaços intercelulares.

Na Tabela 3, estão apresentados os resultados análise sensorial do café conilon dos lotes cereja, mistura e boia depois da secagem em terreiro de concreto e em terreiro híbrido.

Analisando descritivamente os resultados, observa-se que a secagem em terreiro de concreto teve uma tendência a gerar produtos com melhor análise sensorial, uma vez que três amostras de café do terreiro híbrido apresentaram nota 0 e obtiveram características sensoriais depreciativas ao sabor, como por exemplo: fermentado, sujo e oxidado. Por outro lado, a maioria das amostras de café conilon secadas no terreiro de concreto apresentou as características sensoriais de bom corpo, boa doçura e limpo/neutro, indicando melhor qualidade do produto.

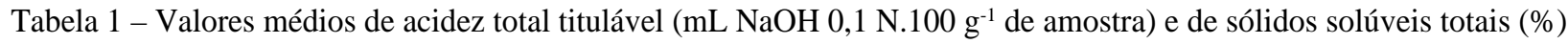
do café conilon dos lotes cereja, mistura e boia depois da secagem em terreiro de concreto e em terreiro híbrido.

\begin{tabular}{cccc}
\hline Terreiro & Lotes de café & Acidez total titulável & Sólidos solúveis \\
\hline \multirow{4}{*}{ Terreiro Híbrido } & Cereja & 258,33 & 27,08 \\
& Mistura & 233,33 & 29,17 \\
& Boia & 241,67 & 25,00 \\
\cline { 2 - 4 } & Média & $244,44 \mathrm{a}$ & $27,08 \mathrm{~b}$ \\
\hline \multirow{3}{*}{ Terreiro de } & Cereja & 225,00 & 33,33 \\
concreto & Mistura & 233,33 & 31,25 \\
& Boia & 208,33 & 29,17 \\
\cline { 2 - 4 } & Média & $222,22 \mathrm{~b}$ & $31,25 \mathrm{a}$ \\
\hline & $\mathrm{CV}(\%)$ & 5,65 & 10,10 \\
\hline
\end{tabular}

Médias seguidas pela mesma letra na coluna não diferem entre si ao nível de 5\% de probabilidade pelo teste Tukey.

Tabela 2 - Valores médios da condutividade elétrica $\left(\mu \mathrm{S} \mathrm{cm}^{-1} \mathrm{~g}^{-1}\right)$ do café conilon dos lotes cereja, mistura e boia depois da secagem em terreiro de concreto e em terreiro híbrido.

\begin{tabular}{ccccc}
\hline \multirow{2}{*}{ Terreiro } & \multicolumn{4}{c}{ Lotes de café } \\
\cline { 2 - 5 } & Cereja & Mistura & Boia & Média \\
\hline Terreiro Híbrido & 122,56 & 105,74 & 108,14 & $112,15 \mathrm{~A}$ \\
Terreiro de concreto & 96,98 & 90,47 & 94,03 & $93,83 \mathrm{~B}$ \\
\hline Média & $109,77 \mathrm{a}$ & $98,11 \mathrm{~b}$ & $101,09 \mathrm{~b}$ \\
\hline
\end{tabular}

Coeficiente de variação $=5,20 \%$

Médias seguidas pela mesma letra maiúscula na coluna e minúscula na linha não diferem entre si ao nível de 5\% de probabilidade pelo teste Tukey. 
Tabela 3 - Classificação por qualidade da bebida do café conilon dos lotes cereja, mistura e boia depois da secagem em terreiro de concreto e em terreiro híbrido.

\begin{tabular}{cccc}
\hline Terreiro & Lotes de café & Nota & Bebida: Observação \\
\hline \multirow{3}{*}{ Terreiro Híbrido } & Cereja & 0 & Verde Fermentado \\
& Cereja & 0 & Sujo \\
& Cereja & 83 & Oxidado \\
\cline { 2 - 4 } & Mistura & 82 & Leve Fermentação \\
\cline { 2 - 4 } & Mistura & 84 & Bom Corpo \\
& Mistura & 79 & Sujo Verde Fermentado \\
\hline & Boia & 83 & Limpo / Neutro \\
& Boia & 0 & Xícaras fermentadas \\
& Boia & 82 & Limpo / Neutro \\
\cline { 2 - 4 } Terreiro de concreto & Cereja & 85 & Bom Corpo \\
& Cereja & 83 & Verde intenso \\
& Cereja & 83 & Sujo / Fermentado Corpo / Boa Doçura \\
\cline { 2 - 4 } & Mistura & 86 & Verde intenso \\
& Mistura & 82 & Limpo / Neutro \\
\cline { 2 - 4 } & Mistura & 82 & Limpo / Neutro \\
& Boia & 82 & Bom Corpo \\
& Boia & 83 & Limpo / Neutro \\
\end{tabular}

Em diversos testes realizados com este sistema de secagem, observou-se que o terreiro híbrido promoveu a obtenção de um café com qualidade superior ao produto submetido à secagem em terreiro de concreto (Donzeles et al., 2007a; Donzeles et al., 2007b; Donzeles et al., 2008). No entanto, não foi o observado neste trabalho, pois de uma forma geral o café submetido à secagem em terreiro de concreto promoveu melhores resultados. Isso pode ter ocorrido em função da espécie de café utilizada, ou mesmo das condições de secagem, uma vez que as condições de temperatura e umidade relativa do Estado de Rondônia promovem a secagem em um tempo menor que os grãos secados no Estado de Minas Gerais. A exemplo disso têmse o trabalho realizado por Resende et al. (2007), onde os grãos de café submetidos à secagem em terreiro de concreto atingiram o teor de água de 10 (\% b.u.) com 117,5 horas, nas condições climáticas do Estado de Rondônia; enquanto que, o trabalho realizado por Donzeles et al. (2007b), no Estado de Minas Gerais necessitou de 350 horas para atingir o teor de água em torno de 12 (\% b.u.) e isso pode ter ocasionado maiores fermentações na massa dos grãos proporcionando um café de pior qualidade.
Borém et al. (2008a), trabalhando com a secagem de café em terreiros e em secador com ar aquecido a $40^{\circ}$ e $60^{\circ} \mathrm{C}$, mostraram que, com a elevação da temperatura de secagem ocorreu aumento na condutividade elétrica, lixiviação de potássio, acidez titulável total e na acidez graxa, e diminuíram os açúcares redutores, os açúcares totais e a qualidade sensorial do café.

\section{CONCLUSÕES}

Os resultados dos testes de secagem do café Conilon (Coffea Canephora Pierre), nas condições climáticas do estado de Rondônia, permitiram concluir que:

- o tempo necessário para que os cafés boia, mistura e cereja atingissem o teor de água de $9,5 \pm 0,5$ (\%b.u.) foi de 168 horas no terreiro de concreto e no terreiro híbrido foi de 48, 54 e 60 horas, respectivamente; e

- analisando os resultados das análises químicas e da bebida do café, pode-se inferir que o café submetido à secagem em terreiro de concreto obteve melhor qualidade em comparação ao café secado em terreiro híbrido, em razão da taxa de remoção de água mais lenta, em média 3,1 vezes menor que no terreiro híbrido, e em função das condições climáticas favoráveis à secagem em terreiro de concreto. 


\section{AGRADECIMENTOS}

Os autores agradecem ao Consórcio Brasileiro de Pesquisa e Desenvolvimento do Café - CBP\&D/Café e ao Programa Nacional de Pesquisa e Desenvolvimento do Café PNP\&D/Café pelo apoio financeiro indispensável à execução do presente trabalho.

\section{REFERÊNCIAS BIBLIOGRÁFICAS}

ABRAHÃO, S.A.; PEREIRA, R.G.F.A.; DUARTE, S.M.daS.; LIMA, A.R.; ALVARENGA, D.J.; FERREIRA, E.B. Compostos bioativos e atividade antioxidante do café (Coffea arabica L.). Ciência e Agrotecnologia, v.34, n.2, p.414-420, mar./abr., 2010.

AFONSO JÚNIOR, P.C.; CORRÊA, P.C.; GONELI, A.L.D.; BOTELHO, F.M. Secagem, armazenamento e qualidade fisiologia de sementes do cafeeiro. Revista Brasileira de Armazenamento, Viçosa, Especial Café, n.9, p.67-82, 2006.

AFONSO JÚNIOR, P. C.; CORRÊA, P. C.; GONELI, A. L. D.; VILARINHO, M. C.; FRANÇA, A. S. Dinâmica da contração volumétrica do fruto de café durante o processo de secagem. Revista Brasileira de

Armazenamento, Viçosa, Especial café.n. 8, p. 29-35, 2004.

AFONSO JÚNIOR, P.C.; CORRÊA, P.C.; OLIVEIRA, T.T.; OLIVEIRA, M.G.A. Avaliação da qualidade de grãos de café preparados por "via seca" e "via úmida" em função da condição e período de armazenamento. Revista Brasileira de Armazenamento, Viçosa, Especial Café, n.3, p.46-53, 2001.

ANDRADE, E. T.; BORÉM, F. M.; HARDOIM, P. R. Cinética de secagem do café cereja, boia e cereja desmucilado, em quatro diferentes tipos de terreiros.

Revista Brasileira de Armazenamento, Viçosa, Especial Café, n.7, p. 37-43, 2003.

\section{AOAC, ASSOCIATION OF OFFICIAL ANALYTICAL} CHEMISTS. Official methods of analyps of the Association of Official Analytical Chemists. 15 ed. Washington, 1990.

BORÉM, F.M.; CORADI, P.C.; SAATH, R.; OLIVEIRA, J.A. Qualidade do café natural e despolpado após a secagem em terreiros e com altas temperaturas. Ciência e Agrotecnologia, Lavras, v. 32, n. 5, p. 1609-1615, 2008a.
BORÉM, F. M.; MARQUES, E. R.; ALVES, E.

Ultrastructural analysis of drying damage in parchment

Arabica coffee endosperm cells. Biosystems

Engineering, London, v.99, n.1, p. 62-66, 2008b.

BRASIL, Ministério da Agricultura e Reforma Agrária. Secretaria Nacional de defesa Agropecuária. Regras para análise de semente. Brasília, 2009. 395p.

CAMPA, C.; BLLESTER, J. F.; DOULBEAU, S.; DUSSERT, S.; HAMON, S.; NOIROT, M.

Trigonelline and sucrose diversity in wild Coffea species. Food Chemestry, Washington, v. 88, p. 3943, Jan. 2004.

CAMPOS, A.T.; MELO, E.C.; SILVA, J.S.E.

Desenvolvimento e análise de um protótipo de secador de camada fixa para café (Coffea arabica L.) com sistema mecânico. Revista Brasileira de Armazenamento, Viçosa, MG, v. 24, n. 2, p. 37-41, 1999.

COFFEE QUALITY INSTITUTE. SCAA Roasting and Cupping Protocol. Disponível em: http:// iwww.coffeeinstitute.org/documents SSCAABRoastingandCuppingProtocol_0ōô.dod. Acesso em: 01 mar. 2010.

CONAB. Companhia Nacional de Abastecimento, disponivel em <http:///www.conab.gov.brìn fev. 2010.

CORRÊA, P.C.; RESENDE, O.; RIBEIRO, D.M. Drying characteristics and kinetics of coffee berry. Revista Brasileira de Produtos Agroindustriais, Campina Grande, v.8, n.1, p.1-10, 2006.

DONZELES, S.M.L.; SILVA, J.S.; CORRÊA, P.C.; MAGALHÃES, E.A.; SILVA, R.N.; MELO, F.A.O. Análise do terreiro híbrido trabalhando com apenas ar aquecido na secagem de café (Coffea arabica L.).

Revista Brasileira de Armazenamento, Viçosa, Especial Café, n.10, p.73-79, 2008.

DONZELES, S.M.L.; SILVA, J.S.; CORRÊA, P.C.; SANTOS, R.R.; MAGALHÃES, E.A. Custos comparativos da secagem de café cereja descascado em dois terreiros secadores. Engenharia na Agricultura, Viçosa, v.15, n.2, p.119-129, 2007a. 
DONZELES, S.M.L.; SILVA, J.S.; LACERDA FILHO, A.F.; MAGALHÃES, E.A.; SANTOS, R.R.

Desenvolvimento e análise de um terreiro híbrido para secagem de café. Engenharia na Agricultura, Viçosa, v.15, n.3, p.261-272, $2007 \mathrm{~b}$.

LACERDA FILHO, A.F.; SILVA, J.S.; SEDIYAMA, G.C. Comparação entre materiais de pavimentação de terreiro para a secagem de café. Revista Brasileira de

Armazenamento, Viçosa, Especial Café, n.9, p.83-93, 2006.

LEITE, I.P.; VILELA, E.R.; CARVALHO, V.D. Efeito do armazenamento na composição física e química do grão de café em diferentes processamentos. Pesquisa Agropecuária Brasileira, Brasília, v. 31, n.3, p. 159-163, 1996.

LINGLE, T. R. The coffee cupper's handbook: a systematic guide to the sensory evaluation of coffee's flavor. 2ed. Washington, Coffee Development Group, 1986. $32 \mathrm{p}$.

LOPES, L.M.V.; PEREIRA, R.G.F.A.; MENDES, A.N.G.; VILELA, E.R.; CARVALHO, V.D. Avaliação da qualidade de grãos de diferentes cultivares de cafeeiro (Coffea arabica L.). Revista Brasileira de Armazenamento, Viçosa, Especial Café, n. 1, p. 3-8, 2000.

PALACIN, J. J. F.; LACERDA FILHO, A. F.; MELO, E. C.; TEIXEIRA, E. C. Secagem combinada de café cereja descascado. Revista Engenharia na Agricultura, Viçosa, n. 17, n.3, p.244-258, 2009.

REINATO, C.H.R.; BORÉM, F.M.; CARVALHO, F.M.; PEREIRA, R.G.F.A. Avaliação técnica, econômica e qualitativa do uso da lenha e do GLP na secagem do café. Revista Brasileira de Armazenamento, Especial Café, n.7, p. 3-9, 2003a.

REINATO, C.H.R.; BORÉM, F.M.; CARVALHO, F.M.; PEREIRA, R.G.F.A. Eficiência de secadores rotativos com diferentes pontos para o controle da temperatura do café. Revista Brasileira de Armazenamento, Viçosa, Especial Café, n.6, p.3-9, 2003b.

RESENDE, O.; ARCANJO, R.V.; SIQUEIRA, V.C.; RODRIGUES, S.; KESTER, A.N.; LIMA, P.P. Influência do tipo de pavimento na secagem de clones de café (Coffea canephora Pierre) em terreiros de concreto e chão batido. Revista Brasileira de Produtos Agroindustriais, Campina Grande, v.9, n.2, p.171-178, 2007.
RESENDE, O.; AFONSO JÚNIOR, P. C.; SIQUEIRA, V. C.; ARCANJO, R. V. Secagem do café (Coffea canephora pierre) em terreiro híbrido para as condições do Estado de Rondônia Revista Brasileira de Armazenamento, Viçosa, Especial Café, n. 11, p, 74-80, 2009a.

RESENDE, O.; ARCANJO, R.V.; SIQUEIRA, V.C.; RODRIGUES, S. Modelagem matemática para a secagem de clones de café (Coffea canephora Pierre) em terreiro de concreto. Acta Scientiarum. Agronomy, Maringá, v.31, n.2, p.189-196, 2009b.

RIBEIRO, D.M.; BORÉM, F.M.; ANDRADE, E.T.; ROSA, S.D.V.F. Taxa de redução de água do café cereja descascado em função da temperatura da massa, fluxo de ar e período de pré-secagem. Revista Brasileira de Armazenamento, Viçosa, Especial Café, n.7, p. 94-107, 2003.

SANTOS, M.A.; CHALFOUN, S.M.; PIMENTA, C.J. Influência do processamento por via úmida e tipos de secagem sobre a composição, físico química e química do café (Coffea arabica L.). Ciência e Agrotecnologia, v.33, n.1, p.213-218, jan./fev., 2009.

SILVA, J.N.; SILVA, J.S.; SOBRINHO, J.C. Consumo específico de energia e rendimento energético de biomassa na secagem de café utilizando secadores leito fixo de dupla camada e de fluxos cruzados. Revista Brasileira de Armazenamento, Viçosa, Especial Café, n.6, p. 19-24, 2003.

SILVA, J.S.; BERBERT, P.A. Colheita, secagem e armazenamento. Viçosa: Aprenda Fácil, 1999. 145p.

SILVA, J.S.; LACERDA FILHO, A.F.; BERBERT, P. A. Secagem e armazenagem de produtos agrícolas. In: SILVA, J.S. Secagem e armazenagem de produtos agrícolas. Viçosa: UFV, 2000. p.395-467.

VIEIRA, R.D. Teste de condutividade elétrica. In: VIEIRA, R.D.; CARVALHO, N.M. Testes de vigor em sementes. Jaboticabal: FUNEP/UNESP, 1994. p.103-132.

VILELA, E.R.; PEREIRA, R.G.F.A. Pós-colheita e qualidade do café. In: Congresso Brasileiro de Engenharia Agrícola: Armazenamento de Processamento de Produtos Agrícolas, 27. Lavras. Anais... Lavras, UFLA, 1998. p.219-274. 